\title{
Outcomes of ocular evisceration and enucleation in the British Armed Forces from Iraq and Afghanistan
}

\author{
Christopher J. Holmes ${ }^{1} \cdot$ Anthony McLaughlin $\mathbb{1}^{1} \cdot$ Tahir Farooq $^{1} \cdot$ John Awad $^{1} \cdot$ Aidan Murray ${ }^{1} \cdot$ Robert Scott $^{2}$
}

Received: 26 September 2018 / Revised: 29 January 2019 / Accepted: 25 March 2019 / Published online: 5 June 2019

(C) The Royal College of Ophthalmologists 2019

\begin{abstract}
Background/Objectives To evaluate outcomes from all British military patients who underwent eye removal during the Iraq and Afghanistan wars.

Subjects/Methods Retrospective case note review of all patients $(n=19)$ who had undergone either evisceration or enucleation, on a database of all military patients repatriated to the Royal Centre for Defence Medicine, Birmingham.

Results Twenty eye removals were performed on 19 patients, of which $14(70 \%)$ were eviscerations and $6(30 \%)$ were enucleations. Orbital wall fractures were seen in $12(61 \%)$ patients, with orbital floor fractures being the most common. The eye removal was a primary procedure in five of fourteen eviscerations, and five of six enucleations. Complications were seen after four $(28.6 \%)$ eviscerations patients and two (33.3\%) enucleations. Postoperative pain was problematic after three (21.4\%) eviscerations but no enucleations. Orbital implants were placed during three of the five primary enucleations, with good outcomes in two. One patient however required implant retrieval and wound washout due to a high risk of infection and communication with the intra-cranial space.

Conclusions Evisceration and enucleation are both viable options in the management of severe ocular trauma in military patients. Evisceration and enucleation have similar complication rates and outcomes, and both have low rates of sympathetic ophthalmia. Primary orbital implants can be at high risk in cases with orbital roof fracture, but can provide good outcomes in select patients.
\end{abstract}

\section{Introduction}

The incidence of ocular trauma sustained in combat has steadily increased over the past 150 years [1], with military surgeons now expecting around $10 \%$ of battlefield casualties to present with eye injuries [2]. Previous studies have shown that $6.6 \%$ of British casualties repatriated from Iraq and Afghanistan suffered military ocular trauma, but only $0.64 \%$ of the eye injuries were considered severe [3]. Amongst those with the most severe ocular injuries,

Meeting presentation: British Oculoplastic Surgery Society annual meeting 2015

\footnotetext{
Christopher J. Holmes

chrisjholmes@ doctors.org.uk

1 University Hospitals, Birmingham, UK

2 Scott Health Ltd, Coatbridge, Scotland
}

evisceration or enucleation may be undertaken with the aim of reducing the chances of sympathetic ophthalmia (SO), controlling pain, replacing volume, and optimising the cosmetic appearance.

Operation TELIC in Iraq (March 2003 to May 2011) and operation HERRICK in Afghanistan (2002 to October 2014) are two of the most recent theatres of war in which the British Armed Forces have been deployed. Since May 2003 eye injuries sustained from either operation have been evacuated either directly to the United Kingdom (UK), or a minority travel via United States (US) facilities in Landstuhl, Germany. On return to the UK, both cohorts of evacuated patients were managed under the Royal Centre for Defence Medicine (RCDM) in Birmingham, giving the unique opportunity to review data for all patients evacuated to the UK. This paper aims to present data on all patients from the British Armed Forces in Iraq and Afghanistan who underwent ocular evisceration or enucleation between May 2003 and August 2015 for war related injuries. 


\section{Methods}

The study was designed as a retrospective, non-comparative interventional case series and registered with the audit department at University Hospitals Birmingham. A database has been collated of all medically repatriated British military personnel requiring hospital admission between May 2003 and August 2015. From these, a total of 19 patients were identified who had undergone ocular evisceration or enucleation.

Data were collected from the patients' paper and electronic medical records at the Queen Elizabeth Hospital Birmingham and Birmingham Midland Eye Centre, and recorded on a Microsoft Excel spreadsheet for analysis. Where available, data collected included: demographic data, time and place of injury, cause and type of ocular injury, associated adnexal and orbital injuries, date and type of surgery, whether eye removal was primary or secondary, implant type and coating, whether implant was primary or secondary, complications, further procedures, and final outcomes including records of cosmesis, comfort, movement, orbital appearance, and lid position. Statistical analysis was largely descriptive due to the low patient numbers, and independent variable Student $T$-tests or Welch's $T$-tests if Levene's test of variance $<0.05$ were used where appropriate.

Evisceration was undertaken by consultant oculoplastic surgeons and as standard involved a thorough clearance of pigmented tissue from the sclera. A two-flap technique was used with additional relaxing incisions around the optic nerve and four posterior relieving incisions. Implants were not dipped in gentamicin and alcohol washes were not used. Closure was with two-flap mattress sutures to the sclera with 4-0 vicryl, and continuous sutures of 6-0 vicryl to the Tenon's layer and then conjunctiva. There were no significant documented deviations from this technique in this case series.

All but one of the enucleations was performed in either Lanstuhl, Germany, or in the first instance at Camp Bastion, Afghanistan by US military ophthalmic surgeons.

\section{Results}

Twenty operations were identified from 19 patients, all of whom were young males (Table 1). All eye injuries were
Table 1 Data on patient demographics, eye and orbital injury and eye removal

\begin{tabular}{lllll}
\hline Characteristic & & $\begin{array}{l}\text { Evisceration } \\
(n=14)\end{array}$ & $\begin{array}{l}\text { Enucleation } \\
(n=6)\end{array}$ & $\begin{array}{l}\text { All procedures } \\
(n=20)\end{array}$ \\
\hline $\begin{array}{l}\text { Number of patients } \\
\text { Mean age (range) }\end{array}$ & & 14 & 5 & 19 \\
Gender & Male & 14 & $24.1(21-25)$ & $24.5(19-38)$ \\
& Female & 0 & 5 & 19 \\
Location of injury & Iraq & $1(7 \%)$ & 0 & 0 \\
Cause of injury & Afghanistan & $13(93 \%)$ & $2(33 \%)$ & $3(15 \%)$ \\
& IED & $13(93 \%)$ & $4(67 \%)$ & $17(85 \%)$ \\
& RPG & $1(7 \%)$ & $3(50 \%)$ & $16(80 \%)$ \\
Side of injury & Hand grenade & 0 & $1(17 \%)$ & $2(10 \%)$ \\
& GSW & 0 & $1(17 \%)$ & $1(5 \%)$ \\
Orbital wall fracture & Right & $6(43 \%)$ & $1(17 \%)$ & $1(5 \%)$ \\
& Left & $8(57 \%)$ & $4(67 \%)$ & $10(50 \%)$ \\
& Any & $6(43 \%)$ & $2(33 \%)$ & $10(50 \%)$ \\
& Floor & $4(29 \%)$ & $6(100 \%)$ & $12(61 \%)$ \\
& Roof & $2(14 \%)$ & $4(67 \%)$ & $8(42 \%)$ \\
Location of eye & Medial & $1(7 \%)$ & $1(17 \%)$ & $3(16 \%)$ \\
removal & Lateral & $3(21 \%)$ & $5(83 \%)$ & $6(32 \%)$ \\
& Camp Bastion & $2(14 \%)$ & $3(50 \%)$ & $7(32 \%)$ \\
& Landstuhl & 0 & $1(17 \%)$ & $3(15 \%)$ \\
& RCDM & $12(86 \%)$ & $1(17 \%)$ & $13(65 \%)$ \\
\hline
\end{tabular}

${ }^{a}$ Improvised explosive device

${ }^{\mathrm{b}}$ Rocket propelled grenade

${ }^{\mathrm{c}}$ Gunshot wound

${ }^{\mathrm{d}}$ Royal Centre for Defence Medicine 
due to high energy trauma, with 19 of 20 sustained from explosive blast trauma. Information on concurrent orbital wall fractures was available for 18 patients. Regarding orbital fractures, those to the orbital floor were the most common followed by the lateral wall, the orbital roof and the medial wall as summarised in Table 1 .

Eye removals were considered primary if they were performed without previous attempt at globe repair. Of the 14 eviscerations, $5(35.7 \%)$ were primary, at a mean of 1.4 days post injury (range $0-3$ ). The remaining 9 were secondary eviscerations performed on average 21.0 days post injury (range 5-40). This compared to five of the six enucleations being primary procedures, at a mean of 0.8 days (range $0-1$ ). The sole secondary enucleation was performed 39 days post injury.

Orbital implants were inserted at the time of evisceration in six (42.9\%) eyes, but none were implanted during primary procedures. Implants were inserted during four $(66.7 \%)$ enucleations, of which three were during primary procedures (Fig. 1). Secondary implants were used in both eyes of one enucleated patient and were implanted 8 weeks post eye removal at his local tertiary hospital.

Data on the type of implant were recorded for 14 procedures. A silicone implant was used in one eye during a primary enucleation performed in 2006, and 13 subsequent implants were acrylic. Implant size was recorded in 12 eyes, with a modal implant size of $20 \mathrm{~mm}$ used in four eyes (range 16-22 mm). There was no association seen between implant size and complications, or with the presence of orbital wall fractures. A vicryl mesh implant coating was used in two enucleated eyes but no coatings were used in eviscerated eyes. Operating time was variably recorded and difficult to interpret as many procedures were performed alongside other surgical teams treating concurrent injuries.

Complications requiring further treatment (Table 2) occurred in four (28.6\%) patients after evisceration, including one patient with implant extrusion (case 1).

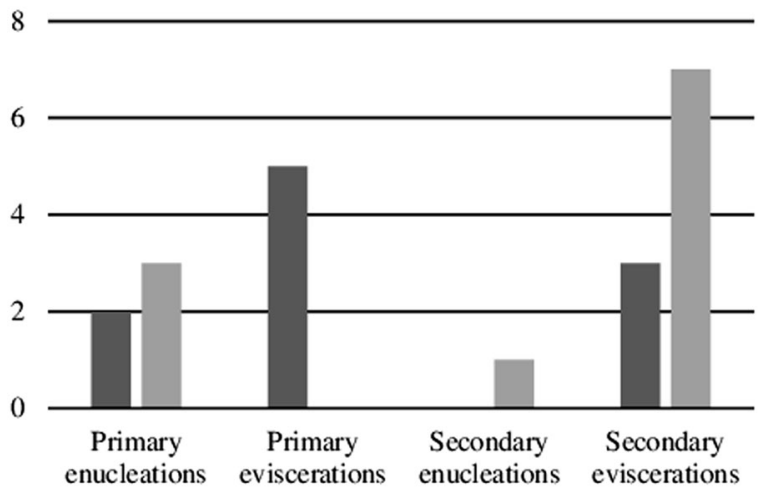

Fig. 1 Frequency of eye removal by procedure and implant. Primary procedures were carried out without prior attempted repair. Primary implants (dark grey) were inserted at the time of eye removal whereas secondary implants (light grey) were inserted in a subsequent procedure
Enucleated patients suffered complications in two (33.3\%) cases, including one who was found to be at high risk of infection, requiring further washout and removal of primary orbital implant (case 2). Details on performing surgeon were available for one enucleation and ten evisceration patients. There were four different consultants that were listed as operating surgeon, but numbers were too small to draw conclusions on individual complication rates (Table 2). Of the 12 patients with orbital wall fractures, $5(41.7 \%)$ suffered complications, compared to none of the patients with intact orbits $(p=0.003)$. Postoperative pain was reported in three $(21.4 \%)$ eviscerated patients but not seen in any enucleated patients, but this did not reach statistical significance $(p=0.241)$. There was no clear relationship between complication rates and time to procedure, and no cases of sympathetic uveitis were recorded in either group.

Long-term outcome data were limited but post-traumatic neuralgia was reportedly controlled in all but one patient by 12 months post injury. This patient was refractory to medical treatment and required a partial trigeminal nerve rhizotomy before gaining adequate symptomatic control 3 years post injury.

Documentation of eye movements and cosmetic outcomes was incomplete, non-standardised, and subjective. Positive comments on cosmesis were recorded in six evisceration patients, but cosmetic outcomes were not remarked upon in enucleation patients. In addition to the complications requiring treatment (Table 2), lid notch repair was required in two patients, and ptosis surgery in one. One patient had insufficient adnexal tissue to support an ordinary ocular prosthesis, and so osseo-integrated implants were inserted to mount an orbital prosthesis to improve cosmesis. One enucleation patient required a dermis fat graft to correct a deep upper lid sulcus.

\section{Case 1}

A 19-year-old male white British soldier suffered an explosive blast injury involving the face from an IED in Afghanistan. After being medically stabilised locally he was evacuated to the Queen Elizabeth hospital Birmingham. On examination he was found to have a right proptosis with a hyphaema, posterior globe rupture, and macula-off retinal detachment. The eye had a dense relative afferent pupillary defect with no perception of light. Computerised tomography (CT) revealed a comminuted fracture of the right lateral orbital wall with a periocular haemorrhage causing the proptosis, but no intraocular foreign bodies. Twentyeight days later he underwent evisceration with primary insertion of an acrylic ball orbital implant. No comment was made on the quality of remaining sclera or ease of closure, and the size of the implant was not recorded. Postoperatively the patient developed implant extrusion and 
Table 2 Post eye removal complications and subsequent management arranged by performing surgeon (pseudonymised) and procedure type. Only one complication of each type was observed

\begin{tabular}{|c|c|c|c|c|c|}
\hline Procedure & Surgeon & $\begin{array}{l}\text { Number of } \\
\text { procedures }\end{array}$ & $\begin{array}{l}\text { Number of } \\
\text { complications }\end{array}$ & Complication & Management \\
\hline \multirow[t]{6}{*}{ Evisceration } & A & 6 & $1(16.7 \%)$ & Implant extrusion & Implant exchange \\
\hline & $\mathrm{B}$ & 2 & 0 & & \\
\hline & $\mathrm{C}$ & 1 & $1(100 \%)$ & Conjunctival implantation cysts & Cyst excision \\
\hline & $\mathrm{D}$ & 1 & 0 & & \\
\hline & Unknown & 4 & $2(50 \%)$ & $\begin{array}{l}\text { Persistent mucopurulent } \\
\text { discharge }\end{array}$ & $\begin{array}{l}\text { Conjunctival excision and split- } \\
\text { skin graft }\end{array}$ \\
\hline & & & & $\begin{array}{l}\text { Postevisceration socket } \\
\text { syndrome }\end{array}$ & Orbital floor implant \\
\hline \multirow[t]{3}{*}{ Enucleation } & $\mathrm{E}$ & 2 & 0 & & \\
\hline & Unknown & 4 & 2 & Discharging, dirty wound & Implant retrieval and washout \\
\hline & & & & $\begin{array}{l}\text { Postenucleation socket } \\
\text { syndrome }\end{array}$ & Orbital floor implant \\
\hline
\end{tabular}

5 months after his initial procedure he underwent implant exchange. Unfortunately, there was a recurrence of implant exposure of 5 months after this. At the patient's request, his care was transferred to a tertiary centre closer to his home.

\section{Case 2}

A 23-year-old male white British soldier in Afghanistan suffered a gunshot wound to the right orbit. He was medically stabilised in Camp Bastion and assessed by the trauma surgeons. On examination, he was found to have a bullet entry wound through the right parietal bone with the likely exit via the orbit, leaving the globe severely disrupted. CT of the head and orbits revealed, alongside significant intracranial pathology, a right orbital floor, roof, and medial wall blow-out fractures (Fig. 2).

Due to the nature of the injury and examination findings the eye was thought to be non-viable and enucleated within hours of his injury. A 16-mm acrylic ball implant was inserted at the time with a vicryl mesh coating. However, after his evacuation to the UK, there was discharge from the socket and it was suspected the wound was contaminated. 48 hours after the patient's primary enucleation he underwent implant retrieval. During the procedure, the implant was sitting very deeply in the orbit due to the severely disrupted anatomy. The wound was grossly contaminated in the presence of leaking cerebrospinal fluid. The implant was removed, a thorough washout performed, and the wound left open. The wound healed well and a secondary implant was placed 8 weeks later. He has since undergone extensive facial reconstructive surgery (Fig. 3) and reported that he was 'fairly happy' with the cosmetic outcome. He was bothered by the sunken appearance of his upper lid however and has been listed for a right orbital dermis fat graft to correct the defect.

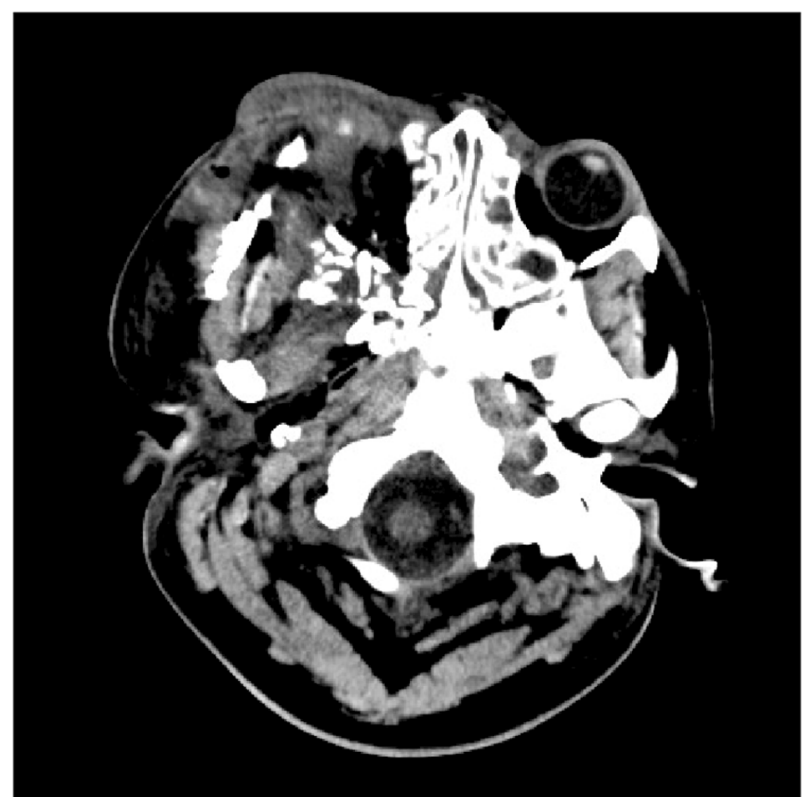

Fig. 2 Computed tomography of head and orbits showing severe disruption to the right globe with medial and lateral wall fractures. Other views also revealed orbital floor and roof blow-out fractures

\section{Discussion}

This is a complete report of all eye removal operations performed on British Armed Forces personnel injured in Iraq and Afghanistan since May 2003. It adds to the sparse available evidence on enucleation and evisceration in the context of severe ocular trauma [4]. Similar to previous literature on military patients, our cohort of patients was all male and young, and the cause of injury was predominately explosive blast trauma $[3,5]$. Unlike previous publications the majority of operations performed were eviscerations. This reflects the preference of UK military surgeons, who 


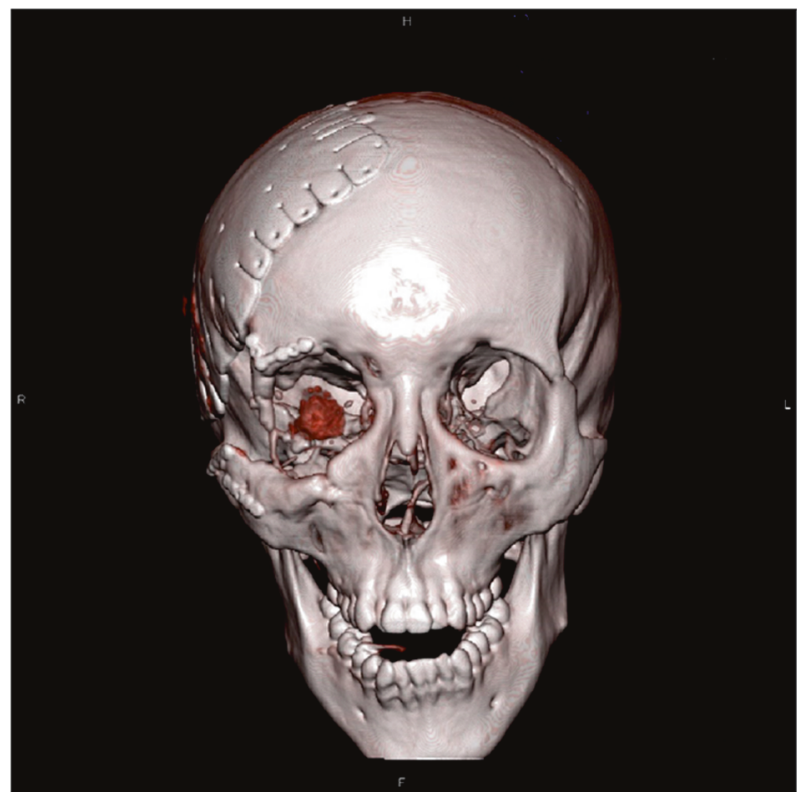

Fig. 3 Three-dimensional reconstruction of head computed tomography after orbital reconstruction and orbital implant removal. Screws and plates are visible over a craniotomy, as well as the right side of the frontal bone, zygoma, and maxilla. The patient went on to have a secondary orbital implant and further orbital reconstruction under the maxillo-facial team

are trained to perform evisceration using a simple technique where the optic nerve is "islandised" to allow the implant to access the intraconal space thereby allowing a larger size to replace volume. Two scleral flaps are also created with two extraocular muscles on each by performing oblique relieving incisions in the sclera. In the trauma cases encountered in our patients, the uvea was not reportedly adherent or difficult to remove. Curettage was sufficient to remove the uveal tissue in all evisceration cases and absolute alcohol debridement was not required. Only one patient underwent enucleation by a UK surgeon. It was unclear why enucleation was favoured over evisceration, and it is likely due to surgeon preference.

The incidence of military ocular trauma appears to have been increasing over time and has been described in up to $13 \%$ of casualties in recent theatres of war [5, 6]. Military ocular trauma is unlike its civilian counterpart in that almost all patients (98\%) are male and the majority (83\%) consist of high-energy explosive blast injuries [5]. Military patients' injuries are accordingly more severe than their civilian counterparts, with $71 \%$ of patients presenting with a visual acuity of $6 / 60$ or worse compared to $27 \%$ of civilians [7]; and $75 \%$ are associated with polytrauma [3], which is relatively uncommon in civilian injuries. The cohort of patients in this case series was at the extreme end of the ocular trauma scale, to the point that $50 \%$ required primary eye removal, a measure reserved for devastating ocular injuries with no prospect of visual potential. Studies of US and British patients from the Iraq and Afghanistan wars have found that rates of eye removal in "severe" ocular injuries were $16 \%$ and $11 \%$, respectively [3,5]. Rates of "severe" ocular injuries appear lower in British military patients compared to their US counterparts, but direct comparison is difficult due to variations in data interpretation. The approach taken by British teams in aeromedically evacuating severe eye injuries to allow assessment in tertiary centres results in an increased time to primary repair (mean 1.9 days) [3] compared to the goal of their US counterparts (within hours of injury) [8], but outcomes appear comparable and this approach may account for the difference in rates of eye removal.

Evisceration holds several advantages over enucleation for surgeons with limited experience as it has been found to take less time $(47.3 \pm 10.3 \mathrm{~min}$ versus $89.6 \pm 10.1 \mathrm{~min}$ [9] $)$ and does not require specific ophthalmic techniques such as slinging and preservation of extraocular muscles. Aesthetic outcome is similar between the two techniques, but some studies have found improved prosthetic motility in evisceration [9-12]. Basic evisceration technique also allows an easy preservation of adequate conjunctiva, and placement of a simple implant such as an acrylic sphere can also be taught to non-specialists. The technique can be taught in a single afternoon to junior surgical trainees using a pig eye wet-lab model. Implant placement in enucleation can be more challenging due to the need to attach the muscles and adequately cover the implant. If no implant can be placed, such as in the field hospital setting, a neatly packed evisceration socket can provide a more convenient environment for a secondary implant procedure than a postenucleation socket.

Enucleation is sometimes preferred over evisceration due to the perception of a reduced risk of SO, particularly outside of the UK. This was reflected in the fact that all patients operated on by non-UK surgeons underwent primary enucleation rather than evisceration. No cases of SO were reported in either cohort, which was expected given its low incidence and the small size of the sample population.

SO is a bilateral, granulomatous pan-uveitis, that can occur months to years after surgery or penetrating trauma to one eye $[13,14]$. The aetiology of SO is not completely understood, but thought to comprise autoimmune and cellmediated mechanisms. The intact eye is immune privileged and lacks lymphatic drainage. In ordinary circumstances immune tolerance is achieved by macrophage presentation of ocular antigens to clusters of B, NKT, and CD4 and CD8 $\mathrm{T}$ cells in the spleen [15-17]. In penetrating injuries, this system of tolerance is bypassed as the conjunctival lymphatics are exposed to uveal antigens [18]. The resulting inflammation affects both the injured and uninjured eye, and is thought to be T cell mediated [13, 19], but B cell infiltration has also been demonstrated [20-23]. 
The antigen exposure at the time of injury is presumed to be limited by timely primary globe closure, or removal of the uveal tissue. Risk factors for SO include a primary repair more than $48 \mathrm{~h}$ post injury, secondary eye removal after 10-14 days, ciliary body involvement in the injury, and a scleral wound greater than $5 \mathrm{~mm}$ in length [14, 24].

$\mathrm{SO}$ is a rare condition and its incidence following penetrating ocular trauma is estimated at between $0.28 \%$ and $1.9 \%[25,26]$. Du Toit et al. found no cases of SO in a series of 491 primary eviscerations over a 10-year period [27]. SO is now readily managed with systemic immunosuppression for severe cases; and in the BOSU study by Kilmartin et al., $75 \%$ of cases followed for a year retained visual acuity of $6 / 12$ or better [28]. Enucleation was traditionally recommended over evisceration to prevent SO $[29,30]$, in spite of Bellan calculations to demonstrate that assuming an incidence of $0.28 \%, 9999$ enucleations would be required to prevent one case of SO [30].

Surgical decision-making in ocular trauma is largely based on surgeon preference and experience, with minimal evidence in the literature to support either enucleation or evisceration. Given the low incidence and treatable nature of SO, evisceration has been shown to be a viable alternative to enucleation [10], and this is supported by the lack of SO in our cohort.

The use of primary orbital implants in eye removal procedures is also contentious. In our cohort, three enucleations were performed as primary procedures, with implants at the time of surgery. Two of these patients went on to have good outcomes with no recorded complications. This demonstrates that in selected patients, orbital implants at the time of primary eye removal can be successful, despite what is by definition a contaminated wound. This approach can be supported by the fact that primary implants can be used in patients undergoing eye removal with endophthalmitis [31], although this does not take into account the disrupted anatomy associated with battlefield orbital trauma and likely contamination of surrounding tissues. The risk of this approach is highlighted in case 2, as this patient required implant retrieval and further washout due to a high risk of infection. The risk in this case was amplified due to the severe trauma to the orbit and communication with the intracranial space. Given that delayed wound closure can reduce infection rates [32], the authors suggest that primary orbital implants should be avoided in cases of severe orbital trauma, particularly where the orbital roof is involved.

Two patients underwent primary evisceration more than $24 \mathrm{~h}$ post injury and went on to have good outcomes, suggesting that their prognosis was not affected by the delay. Although the sample population is small, these findings show that in cases of severe globe disruption, good results can be attained by awaiting specialist review at a tertiary referral centre before eye removal, despite a delay to definitive treatment. This may allow thorough examination, debridement, and decontamination of the wound, while preserving as much tissue as possible. This approach could reduce the requirement for further procedures and enable appropriate selection of patients suitable for primary implants.

Complication rates were similar between eviscerated (28.6\%) and enucleated $(33.3 \%)$ eyes, but higher than the $14 \%$ seen by Zheng $\mathrm{C}$ et al. [4], likely reflecting the greater severity of trauma in battlefield injuries. In this study, complications were higher in patients with orbital wall fractures, again indicating an increased severity of trauma. Given the sample size and dissimilarities between the two groups, further investigation would be required to better define their safety profile. There was no clear association between complications and time to procedure, or with the use of primary or secondary implant insertion. One patient developed implant exposure (case 1) but there were no recorded pre or intra-operative findings that indicated the patient was at high risk. The rate of implant exposure $(5.0 \%)$ compared favourably with the findings of Tabatabaee et al. in traumatised eyes (16.1\%); but it is of note that predominately acrylic implants were used in our cohort rather than porous implants [33]. Our findings of increased rates of postoperative pain in eviscerated patients compared to enucleations corresponds with the findings of Migliori et al. [10].

Collection of data on long-term outcomes was hampered by limited documentation, particularly regarding the extent of eye movement and cosmetic outcome. Long-term data were also limited as British Armed Forces personnel are recruited from all around the UK and whilst their initial management on repatriation was under the RCDM, patients were frequently transferred on to local centres for long-term follow-up.

In summary, evisceration and enucleation are both viable options in the management of severe ocular trauma in military patients. Procedure selection is largely based on surgeon experience and opinion, but evisceration and enucleation have similar complication rates and low rates of $\mathrm{SO}$, although evisceration may be associated with increased postoperative pain. Primary orbital implants can be used in select patients, but wounds must be thoroughly cleaned before this is done and patients with orbital roof fractures should be considered high risk.

\section{Summary}

\section{What was known before}

- Poor availability of data on outcomes of eye removal, especially from military trauma. Military trauma often involves the eyes and is of high energy, and relatively frequently requires eye removal. 
- Unclear on best management of patients requiring eye removal or if evisceration or enucleation is superior technique.

\section{What this study adds}

- Complete overview of ophthalmic trauma patients from the Iraq and Afghanistan wars requiring eye removal. Enucleation and evisceration provide similar complication rates and outcomes, but orbital wall fractures are associated with higher rates of complications.

\section{Compliance with ethical standards}

Conflict of interest The authors declare that they have no conflict of interest.

Publisher's note: Springer Nature remains neutral with regard to jurisdictional claims in published maps and institutional affiliations.

\section{References}

1. Abbotts R, Harrison SE, Cooper GL. Primary blast injuries to the eye: a review of the evidence. J R Army Med Corps. 2007; 153:119-23.

2. Taylor MA, Diamond $\mathrm{T}$ The British Military Surgery Pocket Book. P. Roberts (ed.). $112 \times 188$ mm. Pp. 720. Illustrated. 2004. British Army Publication. Br J Surg. 2006;93:1150. https://doi. org/10.1002/bjs.5548.

3. Blanch RJ, Bindra MS, Jacks AS, Scott RAH. Ophthalmic injuries in British Armed Forces in Iraq and Afghanistan. Eye. 2011; 25:218-23. https://doi.org/10.1038/eye.2010.190.

4. Zheng $\mathrm{C}, \mathrm{Wu} \mathrm{AY}$. Enucleation versus evisceration in ocular trauma: a retrospective review and study of current literature. Orbit. 2013;32:356-61. https://doi.org/10.3109/01676830.2013. 764452.

5. Weichel ED, Colyer MH, Ludlow SE, Bower KS, Eiseman AS. Combat ocular trauma visual outcomes during operations iraqi and enduring freedom. Ophthalmology. 2008;115:2235-45. https:// doi.org/10.1016/j.ophtha.2008.08.033.

6. Heier JS, Enzenauer RW, Wintermeyer SF, Delaney M, LaPiana FP. Ocular injuries and diseases at a combat support hospital in support of Operations Desert Shield and Desert Storm. Arch Ophthalmol. 1993;111:795-8.

7. Kuhn F, Morris R, Witherspoon CD, Mann L. Epidemiology of blinding trauma in the United States Eye Injury Registry. Ophthalmic Epidemiol. 2006;13:209-16. https://doi.org/10.1080/ 09286580600665886.

8. Colyer MH, Chun DW, Bower KS, Dick JSB, Weichel ED. Perforating globe injuries during operation Iraqi Freedom. Ophthalmology. 2008;115:2087-93. https://doi.org/10.1016/j.ophtha. 2008.05.013

9. Yousuf SJ, Jones LS, Kidwell EDJ. Enucleation and evisceration: 20 years of experience. Orbit. 2012;31:211-5. https://doi.org/10. 3109/01676830.2011.639477.

10. Migliori ME. Enucleation versus evisceration. Curr Opin Ophthalmol. 2002;13:298-302.
11. Nakra T, Simon GJBen, Douglas RS, Schwarcz RM, McCann JD, Goldberg RA. Comparing outcomes of enucleation and evisceration. Ophthalmology. 2006;113:2270-5.

12. Tari AS, Malihi M, Kasaee A, et al. Enucleation with hydroxyapatite implantation versus evisceration plus scleral quadrisection and alloplastic implantation. Ophthalmic Plast Reconstr Surg. 2009;25:130-3.

13. Goto H, Rao NA. Sympathetic ophthalmia and Vogt-KoyanagiHarada syndrome. Int Ophthalmol Clin. 1990;30:279-85.

14. Lubin JR, Albert DM, Weinstein M. Sixty-five years of sympathetic ophthalmia. A clinicopathologic review of 105 cases (1913-1978). Ophthalmology. 1980;87:109-21.

15. D'Orazio TJ, Niederkorn JY. Splenic B cells are required for tolerogenic antigen presentation in the induction of anterior chamber-associated immune deviation (ACAID). Immunology. 1998;95:47-55.

16. Lin H-H, Faunce DE, Stacey M, et al. The macrophage F4/80 receptor is required for the induction of antigen-specific efferent regulatory $\mathrm{T}$ cells in peripheral tolerance. $\mathrm{J}$ Exp Med. 2005;201:1615-25. https://doi.org/10.1084/jem.20042307.

17. Sonoda K-H, Stein-Streilein J. Ocular immune privilege and CD1d-reactive natural killer T cells. Cornea. 2002;21(2 Suppl 1): S33-8.

18. Albert DM, Diaz-Rohena R. A historical review of sympathetic ophthalmia and its epidemiology. Surv Ophthalmol. 1989; 34:1-14. https://doi.org/10.1016/0039-6257(89)90125-2.

19. Rao NA, Robin J, Hartmann D, Sweeney JA, Marak GEJ. The role of the penetrating wound in the development of sympathetic ophthalmia experimental observations. Arch Ophthalmol. 1983; 101:102-4.

20. Abu El-Asrar AM, Struyf S, Van den Broeck C, et al. Expression of chemokines and gelatinase B in sympathetic ophthalmia. Eye. 2007;21:649-57. https://doi.org/10.1038/sj.eye.6702342.

21. Auw-Haedrich C, Loeffler KU, Witschel H. Sympathetic ophthalmia: an immunohistochemistry study of four cases. Ger J Ophthalmol. 1996;5:98-103.

22. Aziz HA, Flynn HW, Young RC, Davis JL, Dubovy SR. Sympathetic ophthalmia: clinicopathologic correlation in a consecutive case series. Retina. 2015;35:1696-703. https://doi.org/10.1097/ IAE.0000000000000506.

23. Shah DN, Piacentini MA, Burnier MN, McLean IW, Nussenblatt RB, Chan CC. Inflammatory cellular kinetics in sympathetic ophthalmia a study of 29 traumatized (exciting) eyes. Ocul Immunol Inflamm. 1993;1:255-62. https://doi.org/10.3109/ 09273949309085026

24. Chan CC, Roberge RG, Whitcup SM, Nussenblatt RB. 32 cases of sympathetic ophthalmia. A retrospective study at the National Eye Institute, Bethesda, Md., from 1982 to 1992. Arch Ophthalmol. 1995;113:597-600.

25. Alfaro DV, Liggett PE. Management of the opaque media eye with no light perception. In: Alfaro DVIIILP, editor. Vitreoretinal Surgery of the Injured Eye. Philidelphia, PA, USA: LippincottRaven; 1999:365.

26. Makley TA Jr, Azar A. Sympathetic ophthalmia: a long-term follow-up. Arch Ophthalmol. 1978;96:257-62.

27. du Toit N, Motala MI, Richards J, Murray ADN, Maitra S. The risk of sympathetic ophthalmia following evisceration for penetrating eye injuries at Groote Schuur Hospital. Br J Ophthalmol. 2008;92:61-63. https://doi.org/10.1136/bjo.2007.120600.

28. Kilmartin DJ, Dick AD, Forrester JV. Prospective surveillance of sympathetic ophthalmia in the UK and Republic of Ireland. Br J Ophthalmol. 2000;84:259-263.

29. Bilyk JR. Enucleation, evisceration, and sympathetic ophthalmia. Curr Opin Ophthalmol. 2000;11:372-86. https://doi.org/10.1097/ 00055735-200010000-00015. 
30. Savar A, Andreoli MT, Kloek CE, Andreoli CM. Enucleation for open globe injury. Am J Ophthalmol. 2009;147:595-600.e1. https://doi.org/10.1016/j.ajo.2008.10.017.

31. Hui JI. Outcomes of orbital implants after evisceration and enucleation in patients with endophthalmitis. Curr Opin Ophthalmol. 2010;21:375-9. https://doi.org/10.1097/ICU. 0b013e32833b7a56.
32. Shore JW, Dieckert JP, Levine MR. Delayed primary wound closure. Use Prev implant Extrus evisceration endophthalmitis. Arch Ophthalmol. 1988;106:1303-8.

33. Tabatabaee Z, Mazloumi M, Rajabi MT, et al. Comparison of the exposure rate of wrapped hydroxyapatite (Bio-Eye) versus unwrapped porous polyethylene (Medpor) orbital implants in enucleated patients. Ophthalmic Plast Reconstr Surg. 2011;27:114-8. 